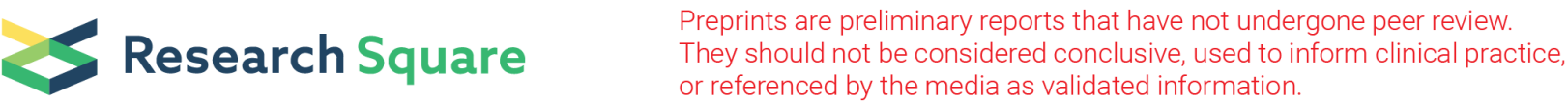

\section{Assessment of the Academic Satisfaction of Graduate Students During the SARS-CoV-2 Pandemic, In An Internal Medicine Department.}

Rodrigo Castro-Paris ( $\square$ rodrigo.castro@javeriana.edu.co)

Hospital Universitario San Ignacio https://orcid.org/0000-0002-4058-312X

Oscar Mauricio Munoz-Velandia

Hospital Universitario San Ignacio

Angel Alberto Garcia-Pena

Hospital Universitario San Ignacio

Daniel Gerardo Fernández-Ávila

Hospital Universitario San Ignacio

Research article

Keywords: Medical Education, COVID-19 Pandemic, SARS-CoV-2, Internal Medicine, Postgraduate education, Academic satisfaction

Posted Date: September 18th, 2020

DOl: https://doi.org/10.21203/rs.3.rs-69949/v1

License: (c) (i) This work is licensed under a Creative Commons Attribution 4.0 International License. Read Full License 


\section{Abstract}

\section{Background}

During the SARS-CoV-2/ COVID-19 pandemic, academic activities have been adjusted to include virtual components. The impact on student satisfaction with their medical education, especially in graduate programs, is unknown.

\section{Methods}

The Internal Medicine Department of the Pontificia Universidad Javeriana and the Hospital Universitario San Ignacio, in Bogotá (Colombia), converted multiple theoretical academic activities to virtual modality, and modified the practical activities using technological platforms that allow remote participation of residents or teachers. A survey was designed to evaluate the satisfaction of residents in relation to the theoretical and practical components, and the perception of change.

\section{Results}

48 residents responded the survey. $>72 \%$ reported being partially or totally satisfied with the organization, content of the activities, interdisciplinary approach and opportunity to discuss topics for the theoretical activities. When evaluating the care activities, $21.9 \%$ of the residents reported not being satisfied with the preparation that those activities give for clinical practice and professional life, and 31.3 $\%$ with the interdisciplinary approach, and time to discuss the cases. $>72.9 \%$ were satisfied with the technological tools used. The level of perceived stress worsened for $62.5 \%$, and the opportunity to develop and practice skills worsened for $64.6 \%$ of those surveyed.

\section{Conclusions}

Despite the high satisfaction with the theoretical activities and the technological tools used, residents consider that the implementation of remote academic activities is associated with higher levels of stress and fewer opportunities to develop and practice clinical skills. New strategies are needed to improve practical components while maintaining social distancing.

\section{Background}

The SARS-CoV-2/COVID-19 pandemic has spread rapidly around the world. During the last week of August 2020, more than 23 million of confirmed cases and 810,000 deaths were reported (1). One of the groups with the highest risk of SARS-CoV-2 contagion are healthcare workers, including training staff, which entails immense challenges to ensure the and learning process (2-4), in particular, when seeking to maintain social distancing measures, one of the most effective interventions to prevent disease transmission $(5,6)$. 
Advances in telecommunications have proven their value and usefulness during disasters and public emergencies (7). In the SARS-CoV-2/COVID-19 pandemic, the use of digital tools has been essential to maintain fast and efficient knowledge exchange, and to achieve the modification of patterns of social relationship, consumption and education(8-14). Its use in medical education requires rapid adaptation and transformation of educational strategies within the medicine schools $(4,15-17)$.

The published information about the difficulties and potential solutions implemented by medical training programs during the pandemic is limited. Some orthopedic, anesthesiology, dermatology and ophthalmology programs have published descriptive studies and editorials sharing their experience(1720). However, the magnitude of the impact of the SARS-CoV-2/COVID-19 pandemic on student satisfaction with medical education, especially in graduate programs, is unknown.

The Internal Medicine Department of the Pontificia Universidad Javeriana and the Hospital Universitario San Ignacio, designed and implemented adjustments to academic activities to include virtual components during the pandemic, aimed to students of first and second specialty programs of the Department. This study assesses the academic satisfaction of residents with the learning environment generated by such changes during the first months of the SARS-CoV-2/COVID-19 pandemic.

\section{Methods}

Due to, the SARS-CoV-2/COVID-19 pandemic, from April 2020 the Department of Internal Medicine of the Pontificia Universidad Javeriana and the Hospital Universitario San Ignacio, converted to virtual mode multiple theoretical academic activities: conferences (classes), research meetings, and multidisciplinary discussions of clinical cases of academic interest. These activities were performed using the educational platform (Blackboard Collaborate $\AA$ ), which allows presentation of information and active participation of students and teachers remotely. The practical academic activities, ceased to perform at the patient's bedside, which was replaced by the patient's face-to-face assessment by one of the team members, and the academic discussion of the findings in a virtual meeting using Microsoft Teams ${ }^{\circledR}$.

To evaluate student satisfaction with the learning environment, and the perception of change, a survey based on multiple questionnaires previously used for the assessment of academic satisfaction $(17,21-$ 34) was designed. The survey was reviewed and tailored in a focus group including professors, students

and methodological experts. The resulting tool was applied in a pilot to a group of seven newly graduated internists, to assess it comprehensibility and easy response. Their comments were taken into account for final adjustments.

Four domains were evaluated: availability and organization of teaching resources; theoretical and practical knowledge learning environment; working environment; and perception of change of academic activities, comparing the face-to-face mode, in the period immediately before the beginning of the pandemic vs the remote mode related to the social distancing regulations. Response options were designed using a Likert-like scale of four options for satisfaction, or five options for change perception assessment. 
We invited all the first specialty residents (Internal Medicine, Dermatology or Geriatrics), and second specialty fellows (Gastroenterology, Cardiology, Pneumology, Endocrinology or Nephrology) to answer the survey. Residents with less than four months since admission to their academic program, and those who were not present in the HUSI during the February to May 2020 period, were excluded. The invitation was sent by institutional email, and the survey was applied through the Google and Forms ${ }^{\circledR}$ application, which ensures that the answers are anonymous, and that each student can only answer them once.

The demographic characteristics of the participants are presented as absolute numbers and proportions, or as central trend measures and dispersion measures, depending on the type of variable and according to whether the normal distribution assumption was met. A Shappiro Wilk test was used to evaluate this assumption. The comparison between subgroups was performed using an $\mathrm{X}^{2}$ test. The analysis was performed using Stata 15 software (StataCorp. 2017. Stata Statistical Software: Release 15. College Station, TX: StataCorp LLC).

\section{Results}

90 residents were invited to participate, 48 (53.3\%) answered the survey. The median age was 27 years (Interquartile range 26-29), most were women (66.7\%) and the academic program with the highest participation was internal medicine $(56.3 \%)$. A greater number of participants were in the first year of residence (39.6\%). The characteristics of the participants are presented in Table 1. 
Table 1

Demographic characteristics $n=48$

\begin{tabular}{|ll|}
\hline Feature & \\
\hline Age-m(IQR) & $27(26-29)$ \\
\hline Female Sex-n(\%) & $32(66.7)$ \\
\hline Academic Program-n(\%) & \\
\hline Internal Medicine & $27(56.3)$ \\
\hline Geriatrics & $10(20.8)$ \\
\hline Dermatology & $5(10.4)$ \\
\hline Cardiology & $1(2.1)$ \\
\hline Gastroenterology & $1(2.1)$ \\
\hline Nephrology & $2(4.2)$ \\
\hline Endocrinology & $1(2.1)$ \\
\hline Current academic year-n(\%) & \\
\hline 1st year resident & $19(39.6)$ \\
\hline 2nd year resident & $13(27.1)$ \\
\hline 3rd year resident & $10(20.8)$ \\
\hline 4th year resident & $1(2.1)$ \\
\hline 1st year fellow & $4(8.3)$ \\
\hline 2nd year fellow & $1(2.1)$ \\
\hline m(Median). IQR(Interquartile range). \\
\hline
\end{tabular}

\section{Academic satisfaction}

Most participants (> 72\%) reported to be partially or completely satisfied with the theoretical activities carried out virtually during the SARS-CoV-2/COVID-19 pandemic, in regard to their organization, content of activities, interdisciplinary approach and opportunity to discuss, teaching supervision and accessibility to teachers. Figure 1a.

First-year residents were more satisfied with the interdisciplinary approach, opportunity and time to discuss in remote activities than senior residents ( $100 \%$ vs $70.4 \% ; p=0.009)$, (supplementary table 1$)$. No other statistically significant differences were found when comparing subgroups based on sex, program or seniority in residence. 
When evaluating practical activities (medical rounds in which at least one member had remote activity), $21.9 \%$ of residents reported not been satisfied with the preparation it gives for clinical practice and professional life, and $31.3 \%$ with the interdisciplinary approach, opportunity and time to discuss cases (Fig. 1b). Satisfaction with the latter topic was greater among men $(91.7 \%$ vs $57.9 \%, p=0.044)$. (Supplementary Table 2).

Respect to the technological tools used, participants mostly (>72.9\%) expressed partial or total satisfaction, with "the training to use the virtual platforms for the development of educational or assistance sessions", "the ease of use of virtual platforms" and "the quality and fluidity of communication provided by platforms and connectivity services that are available to attendees". Satisfaction with "the availability and effectiveness of support groups for the development of educational or attendance sessions" was $60.4 \%$ (Fig. 2). The subgroup analysis found that residents of Internal Medicine were more satisfied with training for the use of virtual platforms than residents and fellows of other specialties $(88.9 \%$ vs $61.9 \%, p=0.027)$. (Supplementary table 3 ).

In regard to the interaction with other health professionals, the participants considered that during the academic activities carried out after the start of the pandemic, their interaction with the team was optimal, they felt part of the team and considered that an attitude of professionalism and respect was promoted, between teachers and residents (proportion of according > 81. 3\%). (Fig. 3).

\section{Perception of change}

The largest number of participants considered that classes and seminars improved by implementing remote measures in the pandemic period $(50.0 \%$ and $53.6 \%$ respectively). Conversely, only a small proportion of participants considered that cases discussions and medical rounds had improved $(29.2 \%$ and $25 \%$ respectively). According to the opinion of the majority of participants, the research meetings quality did not change (45\%). (Fig. 4). No other differences were found when comparing subgroups based on gender, program or seniority in residence.

Overall, $39.6 \%$ of participants considered that the quality of their medical education degraded, and most considered that workloads were higher in the pandemic period ( $62.5 \%$ and $50 \%$ respectively). Similarly, the availability of time for extracurricular activities, perceived stress level and enjoyment of daily activities deteriorated partially or significantly by $50.0 \%, 62.5 \%$ and $43.8 \%$ of respondents respectively. The availability of time for self-study worsened for $43.8 \%$, however, it improved for a similar percentage of individuals. Finally, the opportunity to develop and practice skills deteriorated for $64.6 \%$ of respondents (Fig. 5). (Supplementary table 4).

\section{Discussion}

This study describes the impact on academic satisfaction related to the implementation of remote academic activities as part of postgraduate medical education by measures of social distancing because of the SARS-CoV-2/COVID-19 pandemic. We found that the participants were mostly satisfied with the 
logistical organization, content, accompaniment in activities, technological tools used, and the interaction with other healthcare professionals. Despite this, they consider that the quality of their medical education deteriorated, and the opportunity to develop and practice skills was reduced, with an increase in perceived stress level and a decrease in the enjoyment of their daily activities.

This is not the first pandemic that has forced the reorganization of hospital care and the adjustment of academic activities. New ways of "normality" have been described in emergency situations in health institutions, in different moments and places (35), as described Miller et al (36) during the Spanish Flu in 1918 (37), the epidemic of polio in 1952 (38), and SARS-COV epidemic in 2003. These changes have had consequences for classic methods of medical teaching, including changes in practical components (39, $41,42)$.

In our study, we found high levels of satisfaction with the remote conferences (classes) and seminars, which, by their mainly theoretical nature, do not necessarily require a hospital environment for its development. Similar strategies, based on remote theoretical conferences, have already been previously implemented both in relation to the SARS-CoV-2/COVID-19 pandemic, and in other situations, connecting academic groups in distant regions $(9,10,13-15,17,40,43)$, with good results.

Our findings demonstrate low satisfaction with the medical rounds, suggesting that for the practical components, the accompaniment of a face-to-face teacher is essential. Braniff reported that the face-toface practices (41) improved undergraduate student's perception of their preparedness in five areas: clinical and practical skills, communications skills, teaching and learning, understanding the work environment and team working. The present study reinforces the importance of face-to-face accompaniment for graduate students.

The participants in this study reported high levels of satisfaction, with respect to technological tools and platforms available for virtual activities, being higher among residents of Internal Medicine compared to residents of other specialties. We consider that this difference is related to the creation of a group of residents of internal medicine, who voluntarily and autonomously, promoted practice sessions with the platforms for their peers of the same program. Similar strategies can be used to optimize the acceptance of virtual platforms in other environments.

Despite satisfaction with the technological tools, logistics and content of theoretical academic activities, our data show that residents perceive a greater workload associated with academic and care activities, higher levels of stress, and less enjoyment of daily activities. These findings are consistent with previous publications $(35,40,44-46)$. Meo et al, evaluated the impact of two weeks of quarantine on the mental well-being and learning behaviors of medical students at King Saud University in Riyadh, Saudi Arabia (47). They found high levels of stress and changes in student learning behavior, and approximately $25 \%$ reported depression and discouraging, with feelings of emotional separation from family, friends and peers. Changes perceived by residents may be related to the very nature of the SARS-CoV2/COVID-19 pandemic, with high levels of contagion, without effective treatment, other than prevention measures (44). 
In our knowledge this is the first study evaluating the satisfaction with medical training, and perception of change in postgraduate students of internal medicine and sub-specialties, in relation with strategies including a virtual component implemented during the SARS-CoV2/COVID-19, pandemic. Previous studies have focused mainly on assessing the impact on under graduate students. As limitations, our study had a relatively small sample size, which limited subgroup comparison, however, the response rate was slightly higher than $50 \%$, which is high for this kind of studies considering the voluntary participation, and it was performed at Colombia's largest internal medicine department. A second limitation is that the survey assessed the perception of a relatively short pandemic lapse (2 months). It is unknown if the satisfaction and perception of change could be different in longer periods of time

\section{Conclusions}

Residents and fellows of the Department of Internal Medicine of the Pontificia Universidad Javeriana y el Hospital Universitario in Bogotá (Colombia), are mostly satisfied with the logistics organization, content, accompaniment in activities, technological tools used and interaction with other health professionals. However, they consider that the quality of their medical education deteriorated, the workload worsened, the opportunity to develop and practice skills was reduced as well as the availability of time for self-study and extracurricular activities, with an increase in perceived stress level and a decrease in the enjoyment of their daily activities. These findings suggest that new strategies are needed to improve practical components of medical education while maintaining social distancing.

\section{Abbreviations}

TyP Agreement (Totally Agree and Partially Agree).

Med Int (Residents of Internal Medicine).

Other programs (Residents of Dermatology, Geriatrics, Fellows of Cardiology, Nephrology, Gastroenterology, Endocrinology).

RI (First Year Residents).

RF (Second, Third, Fourth Year Residents and Fellows).

Partially and Significantly Improved (PSI).

Did not Change (DC).

Partially and Significantly Worsened (PSW).

\section{Declarations}

Ethics approval and consent to participate 
The study was approved by the research and ethics committee of the Faculty of Medicine of the Pontificia Universidad Javeriana in Bogotá, Colombia. Committee's reference number FM-CIE-0746-20.

Participation in the survey was voluntary and anonymous, verbal informed consent was obtained from all participants and it was also approved by the research and ethics committee of the Faculty of Medicine of the Pontificia Universidad Javeriana.

Consent for publication

Not applicable.

Availability of data and material

The datasets used and/or analyzed during the current study are available from the corresponding author on reasonable request.

Competing Interest

The authors declare that they have no competing interests.

Funding source: authors.

Authors contributions: All the authors participated in the design, Analysis, and Writing of final manuscript. R.C Collected the data and wrote initial draft.

Acknowledgements

Not applicable.

\section{References}

1. Dong E, Du H GL. An interactive web-based dashboard to track COVID-19 in real time. Lancet Infect Dis 2020; doi:10.1016/S1473-3099(20)30120-1.

2. Characteristics of Health Care Personnel with COVID-19 - United States, February 12-April 9, 2020. MMWR Morb Mortal Wkly Rep 2020;69:477-481.

DOI: http://dx.doi.org/10.15585/mmwr.mm6915e6.

3. Chirico F, Nucera G, Magnavita N. COVID-19: Protecting Healthcare Workers is a priority. Infect Control Hosp Epidemiol. 2020; doi: 10.1017/ice.2020.148.

4. Ashokka B, Ong SY, Tay KH, Loh NHW, Gee CF, Samarasekera DD. Coordinated responses of academic medical centres to pandemics: Sustaining medical education during COVID-19. Med Teach. 2020;0(0):1-10; doi:10.1080/0142159x.2020.1757634

5. Hanalise V. Huff*, MD, MPH; Avantika Singh* MB. Asymptomatic transmission during the COVID-19 pandemic and implications for public health strategies Hanalise. Oxford Univ Press Infect Dis Soc Am. 2019;1-33; doi:10.1093/cid/ciaa654. 
6. Organización Panamericana de la Salud. Respuesta a la pandemia de covid-19 reunión de alto nivel de los ministros de salud. Ops. 2020;10:1-4; ISBN 9789241516839.

7. Lurie N, Carr BG. The role of telehealth in the medical response to disasters. JAMA Intern Med. 2018;178(6):745-6; doi:10.1001/jamainternmed.2018.1314.

8. Sclater K, Alagiakrishnan K, Sclater A. An investigation of videoconferenced geriatric medicine grand rounds in Alberta. 2004; doi: 10.1258/135763304773391558.

9. Cook A, Salle JLP, Reid J, Chow KF, Kuan J, Razvi H, et al. Prospective evaluation of remote, interactive videoconferencing to enhance urology resident education: The genitourinary teleteaching initiative. J Urol. 2005;174(5):1958-60; doi:10.1097/01.ju.0000177483.65528.40.

10. Spitzer RF, Kives S, Ornstein M, Caccia N, Stephens D, Flood C, et al. Videoconferencing for Resident Teaching of Subspecialty Topics: The Pediatric and Adolescent Gynecology Experience at the Hospital for Sick Children. J Pediatr Adolesc Gynecol. 2008;21(6):343-6; doi: 10.1016/j.jpag.2007.09.007.

11. Huang KJ, Cen G, Qiu ZJ, Jiang T, Cao J, Fu CY. Application of international videoconferences for continuing medical education programs related to Laparoscopic Surgery. Telemed e-Health. 2014 Feb 1;20(2):157-60; doi:10.1089/tmj.2013.0070.

12. Boatin A, Ngonzi J, Bradford L, Wylie B, Hospital MG, Medical H. Education across Two Continents. Open J Obstet Gynecol. 2015;5(13):754-61; doi: 10.4236/ojog.2015.513106.Teaching.

13. Stokes W, Ruzycki S, Jainarine R, Isaac D, Cole J. The Canada-Guyana medical education partnership: using videoconferencing to supplement post-graduate medical education among internal medicine trainees. Can Med Educ J. 2017;8(2):e18-24; doi: 10.36834/cmej.36845.

14. Gonzales-Zamora JA, Alave J, De Lima-Corvino DF, Fernandez A. Videoconferences of Infectious Diseases: An educational tool that transcends borders. A useful tool also for the current COVID-19 pandemic. Infez Med. 2020;28(2):135-138.

15. Coleman CG, Law KL, Spicer JO. \#EducationInTheTimeOfCOVID: Leveraging Social Media to Teach during Pandemic Pandemonium. Med Educ. 2020;0-2.

16. Kanneganti A, Sia C-H, Ashokka B, Ooi SBS. Continuing medical education during a pandemic: an academic institution's experience. Postgrad Med J. 2020;postgradmedj-2020-137840.

17. Balasopoulou A, Kokkinos P, Pagoulatos D, Plotas P, Makri OE, Georgakopoulos CD, et al. COVID-19 crisis and residency education: A moment to seize the opportunity and create a new road map. BMC Ophthalmol. 2017;17(1):1.

18. Kogan M, Klein SE, Hannon CP, Nolte MT. Orthopaedic Education During the COVID-19 Pandemic. J Am Acad Orthop Surg. 2020;28(11):e456-e464. doi:10.5435/JAAOS-D-20-00292.

19. Dost B, Koksal E, Terzi Ö, Bilgin S, Ustun YB, Arslan HN. Attitudes of Anesthesiology Specialists and Residents toward Patients Infected with the Novel Coronavirus (COVID-19): A National Survey Study. Surg Infect (Larchmt). 2020;21(4):349-55.

20. Oldenburg R, Marsch A. Optimizing teledermatology visits for dermatology resident education during the COVID-19 pandemic. J Am Acad Dermatol. 2020;82(6):e229. doi:10.1016/j.jaad.2020.03.097. 
21. Colbert-Getz JM, Kim S, Goode VH, Shochet RB, Wright SM. Assessing medical students and residents perceptions of the learning environment: Exploring validity evidence for the interpretation of scores from existing tools. Acad Med. 2014;89(12):1687-93.

22. Seelig CB. Quantitating qualitative issues in residency training: development and testing of a scaled program evaluation questionnaire. J Gen Intern Med. 1993;8(11):610-613. doi:10.1007/BF02599716.

23. Boor K, Van Der Vleuten C, Teunissen P, Scherpbier A, Scheele F. Development and analysis of DRECT, an instrument measuring residents' learning climate. Med Teach. 2011;33(10):820-7.

24. Byrne JM, Loo LK, Giang D. Monitoring and improving resident work environment across affiliated hospitals: A call for a national resident survey. Acad Med. 2009;84(2):199-205.

25. Bloomfield L, Subramaniam R. Development of an instrument to measure the clinical learning environment in diagnostic radiology. J Med Imaging Radiat Oncol. 2008;52(3):262-8.

26. Clapham M, Wall D, Batchelor A. Educational environment in intensive care medicine - Use of Postgraduate Hospital Educational Environment Measure (PHEEM). Med Teach. 2007;29(6):184-91.

27. Roth LM, Severson RK, Probst JC, Monsur JC, Markova T, Kushner SA, et al. Exploring physician and staff perceptions of the learning environment in ambulatory residency clinics. Fam Med. 2006;38(3):177-84.

28. Mulrooney A. Development of an instrument to measure the Practice Vocational Training Environment in Ireland. Med Teach. 2005;27(4):338-42.

29. Fahy BN, Todd SR, Paukert JL, Johnson ML, Bass BL. How accurate is the accreditation council for graduate medical education (ACGME) resident survey? Comparison between ACGME and in-house GME survey. J Surg Educ. 2010;67(6):387-92.

30. England E, Kanfi A, Flink C, Vagal A, Sarkany D, Patel MD, et al. Radiology Residency Program Management in the COVID Era - Strategy and Reality. Acad Radiol. 2020;1-7.

31. Holt KD, Miller RS, Philibert I, Heard JK, Nasca TJ. Residents' perspectives on the learning environment: Data from the accreditation council for graduate medical education resident survey. Acad Med. 2010;85(3):512-8.

32. Cassar K. Development of an instrument to measure the surgical operating theatre learning environment as perceived by basic surgical trainees. Med Teach. 2004;26(3):260-4.

33. Holt MC, Roff S. Development and validation of the Anaesthetic Theatre Educational Environment Measure (ATEEM). Med Teach. 2004;26(6):553-8.

34. Keitz SA, Holland GJ, Melander EH, Bosworth HB, Pincus SH. The veterans affairs learners' perceptions survey: The foundation for educational quality improvement. Acad Med. 2003;78(9):910-7.

35. Newman NA, Lattouf OM. Coalition for medical education-A call to action: A proposition to adapt clinical medical education to meet the needs of students and other healthcare learners during COVID19. J Card Surg. 2020;35(6):1174-5. 
36. Miller DG, Pierson L, Doernberg S. The Role of Medical Students During the COVID-19 Pandemic. Ann Intern Med. 2020;(April):19-21.

37. Starr I. Influenza in 1918: Recollections of the epidemic in Philadelphia. Ann Intern Med. 2006;145(2):138-40.

38. West JB. The physiological challenges of the 1952 Copenhagen poliomyelitis epidemic and a renaissance in clinical respiratory physiology. J Appl Physiol. 2005;99(2):424-32.

39. Moszkowicz D, Duboc H, Dubertret C, Roux D, Bretagnol F. Daily medical education for confined students during coronavirus disease 2019 pandemic: A simple videoconference solution. Clin Anat. 2020;33(6):927-928. doi:10.1002/ca.23601.

40. Zhou T, Huang S, Cheng J, Xiao Y. The distance teaching practice of combined mode of massive open online course micro-video for interns in emergency department during the COVID-19 epidemic period. Telemed e-Health. 2020 May 1;26(5):584-8.

41. Braniff C, Spence RA, Stevenson M, Boohan M, Watson P. Assistantship improves medical students' perception of their preparedness for starting work. Med Teach. 2016;38(1):51-8.

42. Nguyen HT, Do BN, Pham KM, Kim GB, Dam HTB, Nguyen TT, et al. Fear of COVID-19 scaleassociations of its scores with health literacy and health-related behaviors among medical students. Int J Environ Res Public Health. 2020;17(11):1-14.

43. Ferrel MN, Ryan JJ. The Impact of COVID-19 on Medical Education. Cureus. 2020;12(3):10-3.

44. Choi B, Jegatheeswaran L, Minocha A, Alhilani M, Nakhoul M, Mutengesa E. The impact of the COVID-19 pandemic on final year medical students in the United Kingdom: A national survey. BMC Med Educ. 2020;20(1):1-11.

45. Meo SA, Abukhalaf AA, Alomar AA, Sattar K, Klonoff DC. Covid-19 pandemic: Impact of quarantine on medical students' mental wellbeing and learning behaviors. Pakistan J Med Sci. 2020;36(COVID19-S4):S43-8.

\section{Figures}

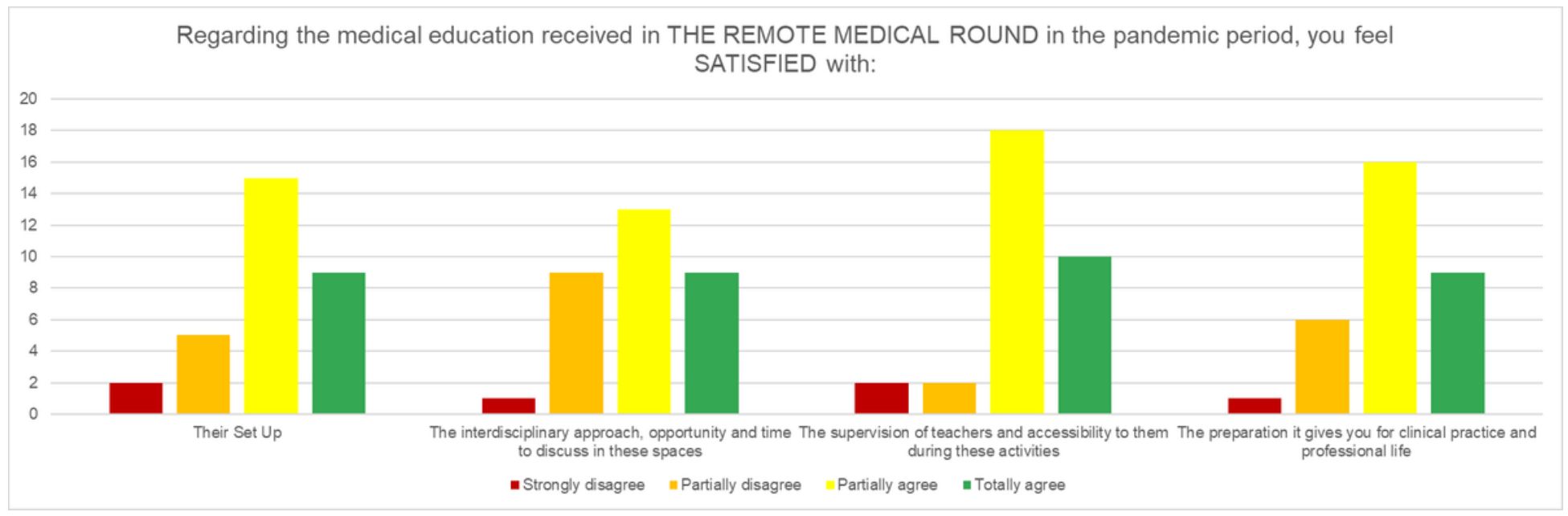


Figure 1

Residents satisfaction with the different theoretical academic activities of the Department of Internal Medicine.

Regarding the medical education received in CONFERENCES (Classes), SEMINARS, DISCUSSIONS OF REMOTE CASES OR RESEARCH MEETINGS in the period of pandemic, you feel satisfied with:

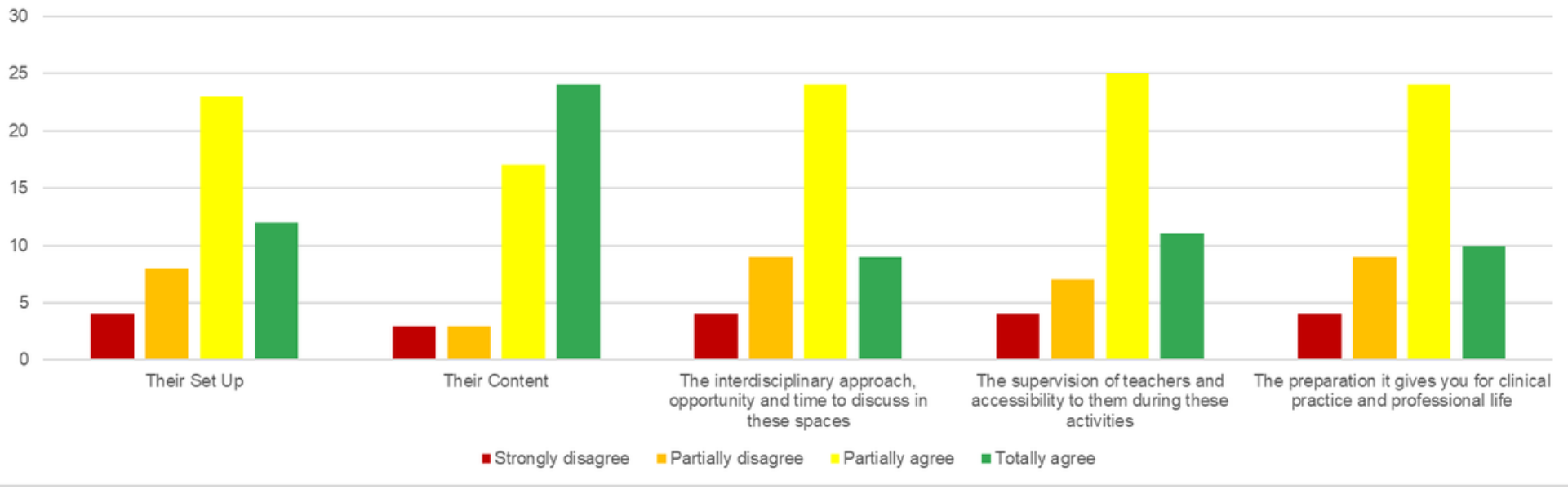

\section{Figure 2}

Residents' satisfaction with Medical Rounds in which at least one member has remote activity.

With regard to the TECHNOLOGICAL TOOLS used for medical education in the first months of physical distancing because of the COVID-19 pandemic, you feel SATISFIED with:

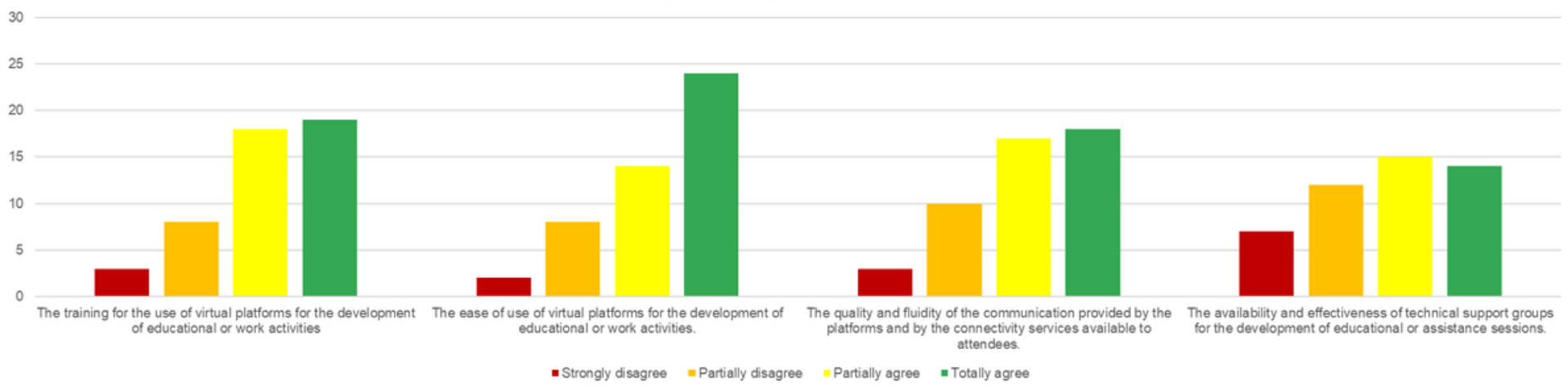

\section{Figure 3}

Satisfaction with the Technological Tools used in the first months of the SARS-CoV-2-COVID-19 pandemic. 
Regarding INTERACTION WITH OTHER HEALTH PROFESSIONALS while developing the medical educational activities during the pandemic period, you consider that:

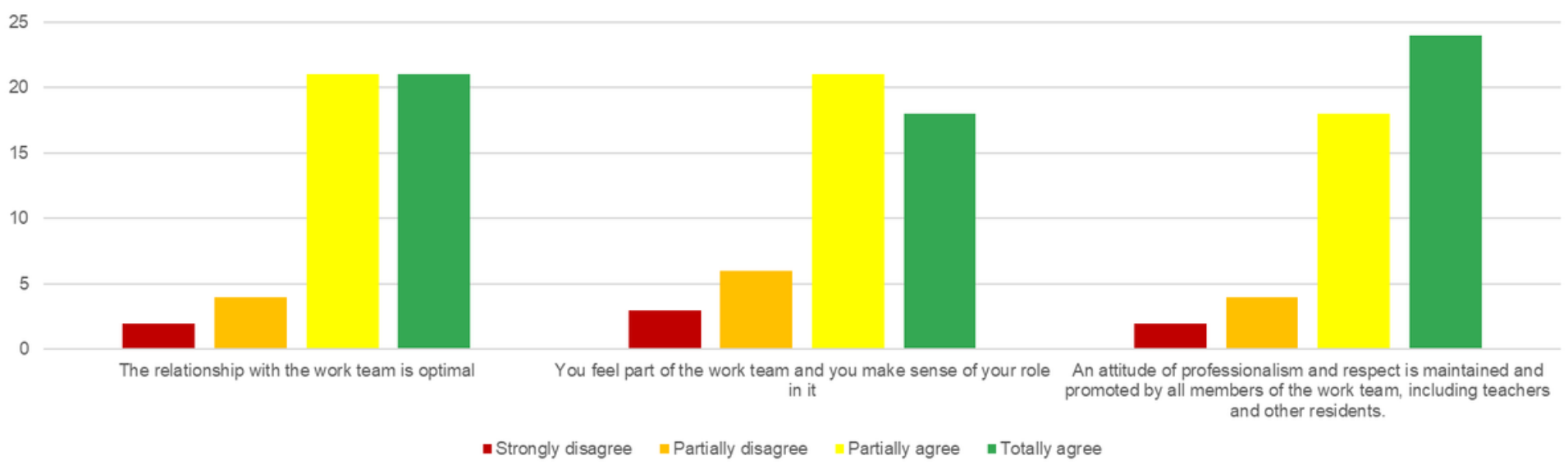

Figure 4

Satisfaction regarding interaction with other healthcare professionals, during the pandemic period of SARS-CoV-2-COVID-19.

Comparing the period of the months of February and March 2020 prior the COVID-19 pandemic, with those of April and May 2020 in which remote measures for medical education were already established, you consider that the following
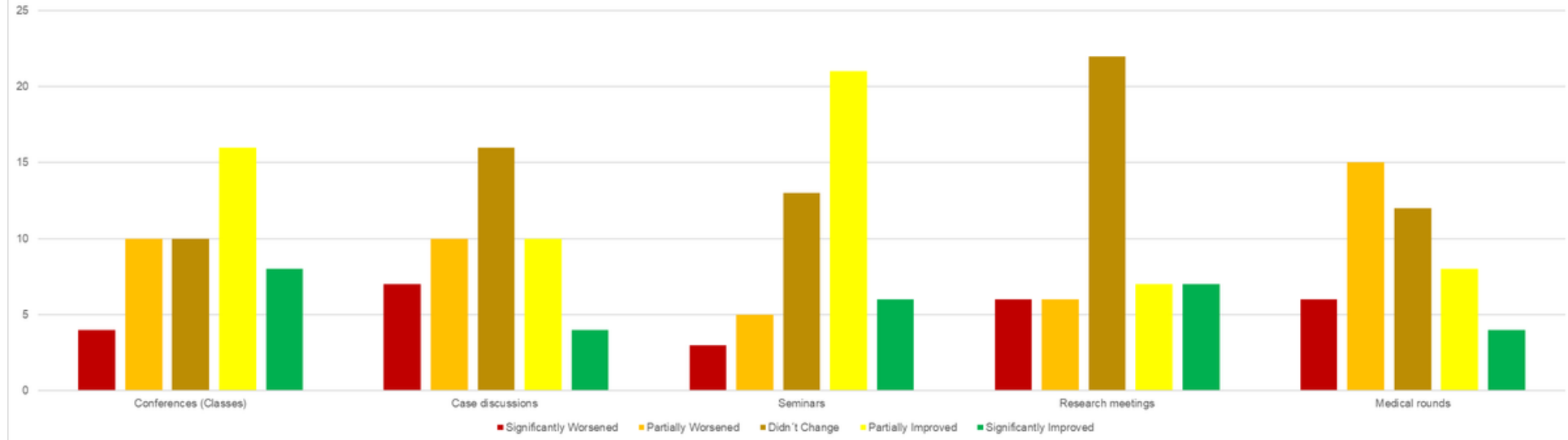

Figure 5

Perception of change with respect to the academic activities in the predemic and pandemic periods.

Comparing the period of the months of February and March 2020 prior to the SARS-CoV-2/COVID-19 pandemic, with those of April and May 2020 in which remote measures for medical education were already in place, you consider that:

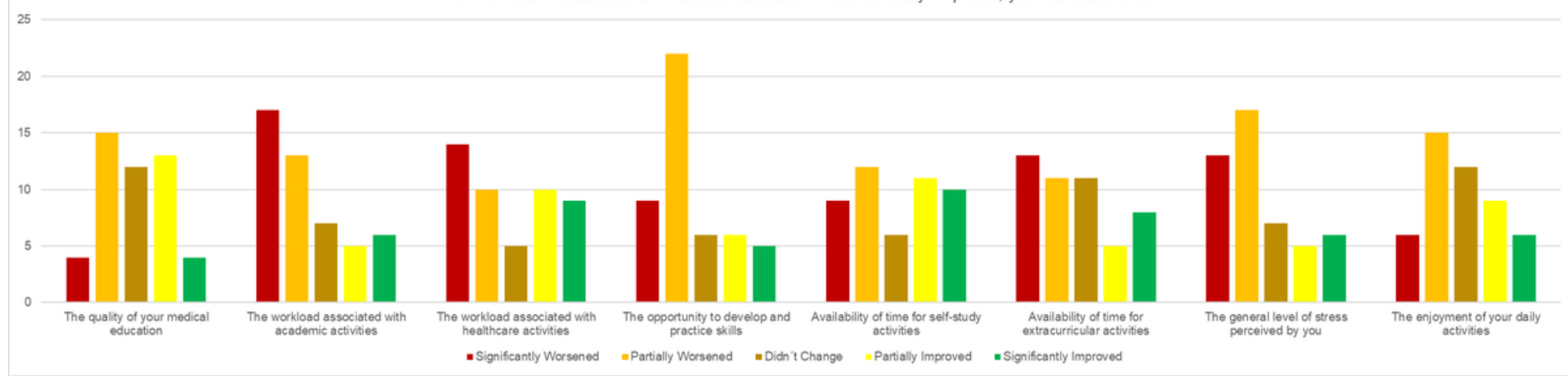


Figure 6

Perception of change with respect to the working environment.

\section{Supplementary Files}

This is a list of supplementary files associated with this preprint. Click to download.

- Supplementarry.docx

- copyofthequestionnaireused.docx 